\title{
CONSERVAÇÃO E RESTAURO DE CERÂMICAS ARQUEOLÓGICAS: WORKSHOP
}

\section{Introdução}

No período de 25 a 29 de julho de 2000 , ocorreu no MAE/USP o workshop "Conservação e Restauro de Cerâmicas Arqueológicas". Este evento foi promovido pelo Museu de Arqueologia e Etnologia da Universidade de São Paulo, British Museum e Associação Brasil +500 Anos. Dirigido apenas para conservadores de instituições brasileiras, foi ministrado por Janet Quinton, Conservadora Sênior do Museu Britânico de Londres, no Laboratório de Conservação e Restauro do MAE/USP como parte das atividades preparatórias para a exposição Unknown Amazon, que será aberta em outubro de 2001, no Museu Britânico.

\section{Amazônia Desconhecida}

A idéia de um workshop de conservação e restauro de cerâmicas arqueológicas começou a ser discutida desde as primeiras visitas à Reserva Técnica do MAE/USP, quando os curadores da exposição Unknown Amazon, Prof. Dr. Eduardo Góes Neves (MAE/USP), Cristiana Barreto (Associação Brasil +500 Anos) Prof. Dr. Colin McEwan (British Museum) selecionavam as peças. Eles constataram essa necessidade ao visitarem as instituições que emprestariam os objetos para a mostra itinerante promovida pela Associação Brasil +500 Anos em parceria com o British Museum. A diversidade de estados de conservação em que se encontrava a maioria das peças levou à exigência de observá-las sob um contexto mais uniforme. Muitas delas já haviam passado por diversas intervenções, sem critérios compatíveis com a conservação científica; algumas precisavam de cuidados imediatos, sem os quais estariam com sua integridade física ameaçada; outras ainda estavam com camadas de terra de escavação. A partir daí, começaram a trabalhar com a possibilidade de um workshop que congregaria os conservadores ou responsáveis pelas coleções dos principais museus que cederiam peças para esta mostra. De acordo com Cristiana Barreto, este workshop teria a possibilidade de assegurar que as peças expostas seriam restauradas e conservadas em seus museus de origem dentro de um mesmo padrão, permitindo que os participantes das várias instituições envolvidas pudessem tomar contato com as técnicas mais avançadas nesta área de conservação e restauro, na qual, sem dúvida, o British Museum é mundialmente reconhecido.

O Laboratório de Conservação do MAE/ USP, apesar de suas pequenas dimensões, foi escolhido por ser o mais bem equipado e pelo nosso próprio envolvimento anterior na "Mostra do Redescobrimento". Também o MAE/USP contava com salas de aula e coleções com todas as características citadas anteriormente.

As instituições convidadas que enviaram representantes para o worshop foram:

- Museu Paraense Emílio Goeldi; ${ }^{1}$

- Museu Nacional da Universidade Federal do Rio de Janeiro; ${ }^{2}$ Janeiro; ${ }^{3}$

- Museu do Índio FUNAI, do Rio de

Por nossa sugestão, Cristiana Barreto convidou um representante do CECOR, ${ }^{4}$ Centro de Conservação e Restauração da Escola de Belas Artes da Universidade Federal de Minas Gerais, como forma de possibilitar a divulgação (efeito multiplicador) dos conhecimentos e dessa experiência neste que é um dos

(1) Vera Lúcia Calandrini Guapindaia (Curadora das coleções arqueológicas) e Raimundo Teodorio dos Santos.

(2) Ângela Maria Camardela Rabello (Arqueóloga, assistente de curadoria das coleções arqueológicas) e Fátima Nascimento (Antropóloga, curadora das coleções etnográficas).

(3) Lucia Bastos (Restauradora).

(4) Moema Nascimento Queiroz (Especialista em conservação e restauração de bens culturais móveis). 
únicos centros especializados em formação profissional de conservadores em nosso país.

A parceria estabelecida possibilitou a vinda de dois profissionais do departamento de conservação do British Museum: Janet Quinton, Conservadora Sênior da área de materiais inorgânicos, quem ministrou o curso; Barbara Wills, Conservadora Sênior da área de materiais orgânicos.

$\mathrm{Na}$ abertura do evento, houve os pronunciamentos da Profa. Dra. Maria Isabel D'Agostino Fleming, representando o MAE/USP, do Sr. Rene Parrini, representando a Associação Brasil +500 Anos, de Cristiana Barreto, representando os curadores. Em seguida, Janet Quinton apresentou a palestra "The British Museum: A Potted History (Uma breve história do Museu Britânico e seu departamento de conservação)", aberta ao público em geral, com a participação de Barbara Wills. ${ }^{5}$

\section{Workshop}

Estabeleceu-se uma metodologia para o workshop: manhãs com aulas teóricas tendo como material didático a apresentação de diapositivos seguida de discussões entre os participantes e os professores, referentes às respectivas experiências e tardes, com aulas práticas no Laboratório do MAE.

Os temas abordados às manhãs foram:

- apresentações do grupo participante e as diretrizes do encontro, com uma explanação sobre as idéias básicas sobre a exposição "Unknown Amazon"; dos professores convidados com um breve histórico do British Museum e sua filosofia de atuação; dos departamentos de conservação e restauração do British Museum e seu corpo técnico e administrativo;

- critérios de conservação e restauração adotados no British Museum;

- distribuição de material didático para o curso e de divulgação do British Museum;

- discussão sobre os processos de conservação e restauração, como limpeza,

(5) Para facilitar a comunicação, a Associação Brasil +500 Anos contratou um serviço de tradução simultânea, disponível durante todo o workshop. refixação de camadas de pintura decorativa ou cerâmicas em desprendimento e suas conseqüências, consolidação de fraturas e rachaduras, remontagem de obras e métodos de preenchimento de lacunas e a possibilidade de reinterpretação de perdas;

- conferência sobre conservação e restauração de materiais orgânicos, proferida por Barbara Wills e de materiais inorgânicos, proferida por Janet Quinton;

Os trabalhos práticos às tardes tiveram a seguinte seqüência:

- distribuição do material didático (kit individual) ${ }^{6}$ com explicações sobre a utilização e função dos diversos materiais a serem usados, suas aplicabilidades, composição química, fatores de risco e segurança no manuseio etc.;

- escolha de peças arqueológicas do acervo do MAE/USP que apresentavam problemas para a discussão, demonstração de procedimentos e exercícios práticos ${ }^{7}$. Cada participante ficou com uma peça e pode experimentar técnicas diversas de limpeza;

- preparação dos adesivos a serem utilizados com explicações teóricas sobre os produtos;

- técnicas de limpeza de fragmento arqueológico (peças cedidas pelo MAE): limpeza a seco, limpeza com solventes, limpeza com jato de vapor;

- fragmentação proposital de um vaso cerâmico (material didático) para as práticas no

(6) Durante os meses de preparação deste workshop, Janet Quinton e o coordenador do Laboratório de Conservação e Restauro do MAE/USP mantiveram uma correspondência eletrônica para a definição de quais materiais eram encontrados no mercado brasileiro e quais deveriam ser importados da Inglaterra. Janet Quinton efetuou as compras na Inglaterra e Gedley Braga as compras no Brasil. A Associação Brasil +500 Anos realizou a importação e cobriu todos os custos dos materiais encontrados no mercado nacional. Alguns solventes e os equipamentos de laboratório foram fornecidos pelo MAE/USP.

(7) Uma seleção prévia do material que poderia trazer mais discussões e oportunidades de experiências já havia sido feita por Janet Quinton e Gedley Braga no dia anterior ao início oficial do workshop. 


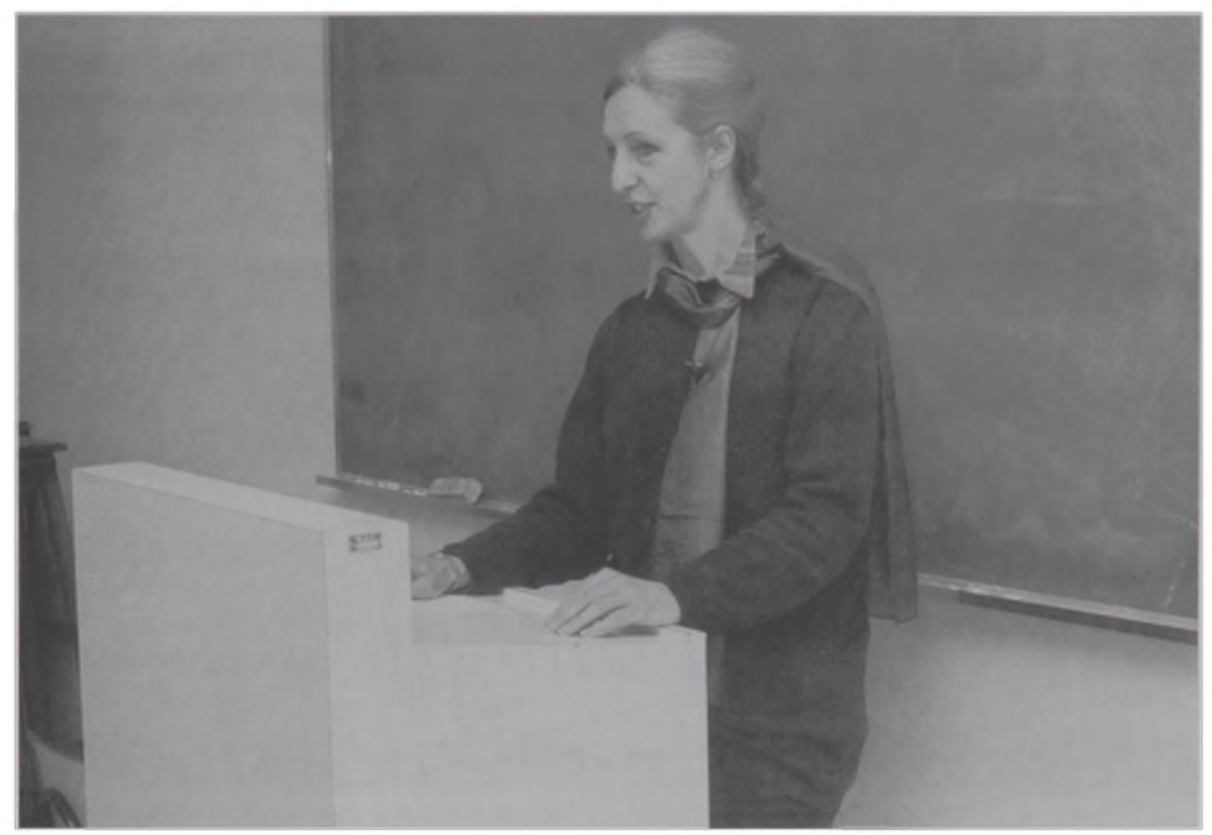

\section{Conferência de Janet Quinton.}

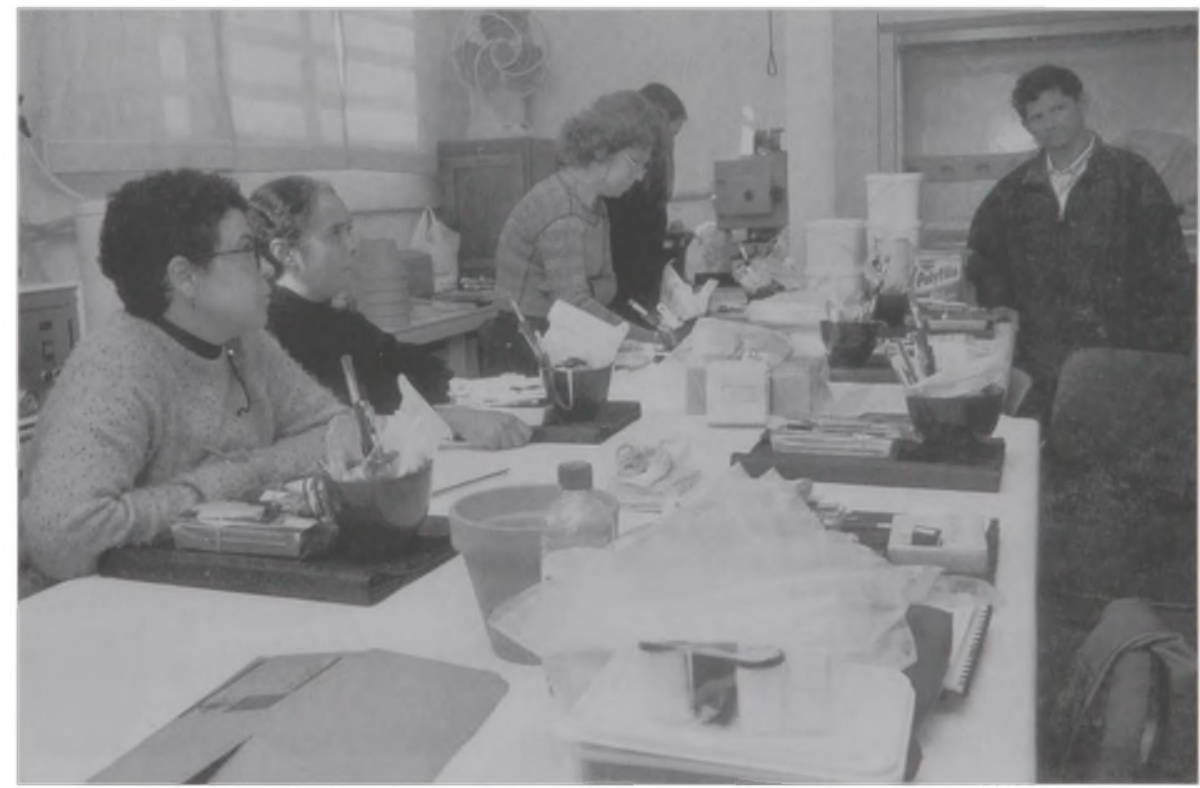

Trabalhos práticos.

laboratório utilizando a metodologia usada pelos departamentos de conservação e restauração do British Museum. Os procedimentos de reorganização dos fragmentos permitiram testes com os diversos tipos de adesivos preparados e/ou disponíveis, complementações e preenchimentos. Cada participante foi orientado a levar para suas 


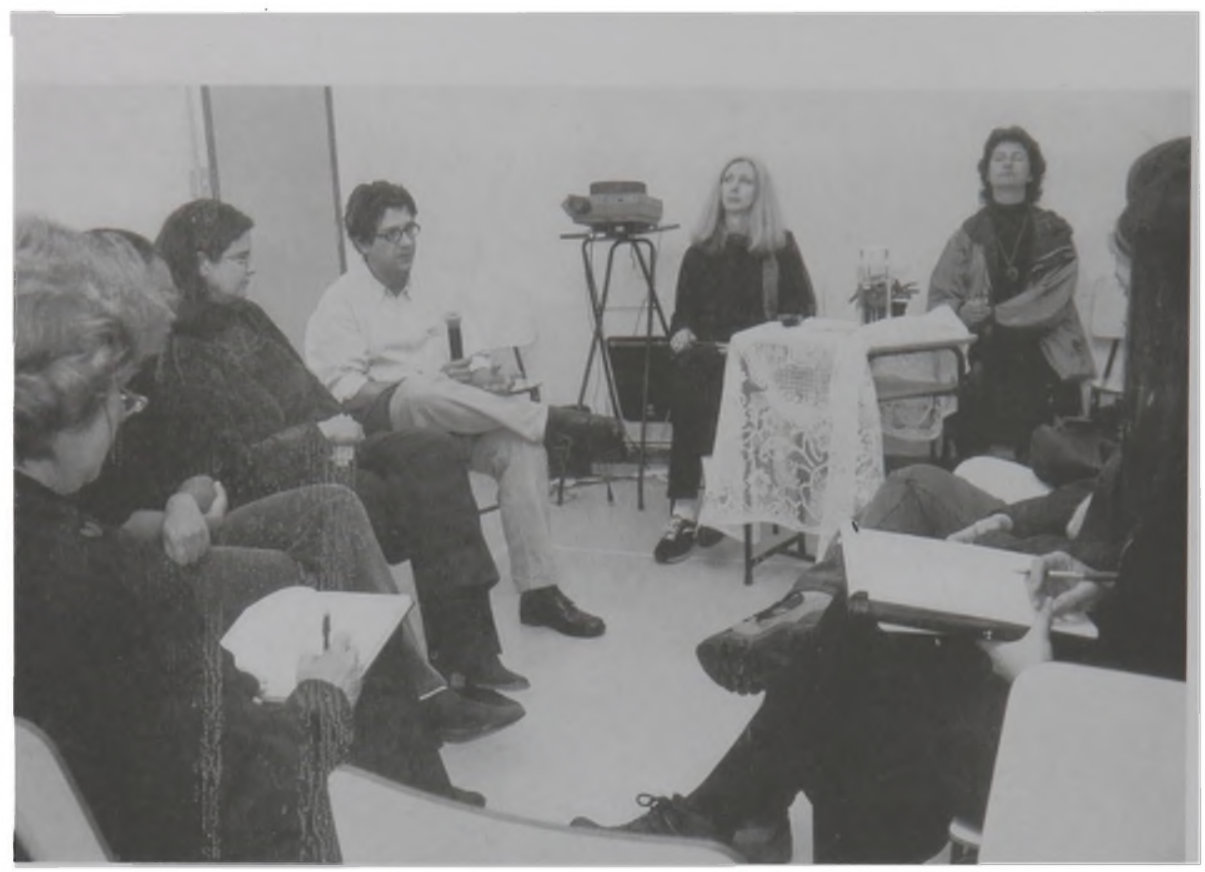

\section{Seminário.}

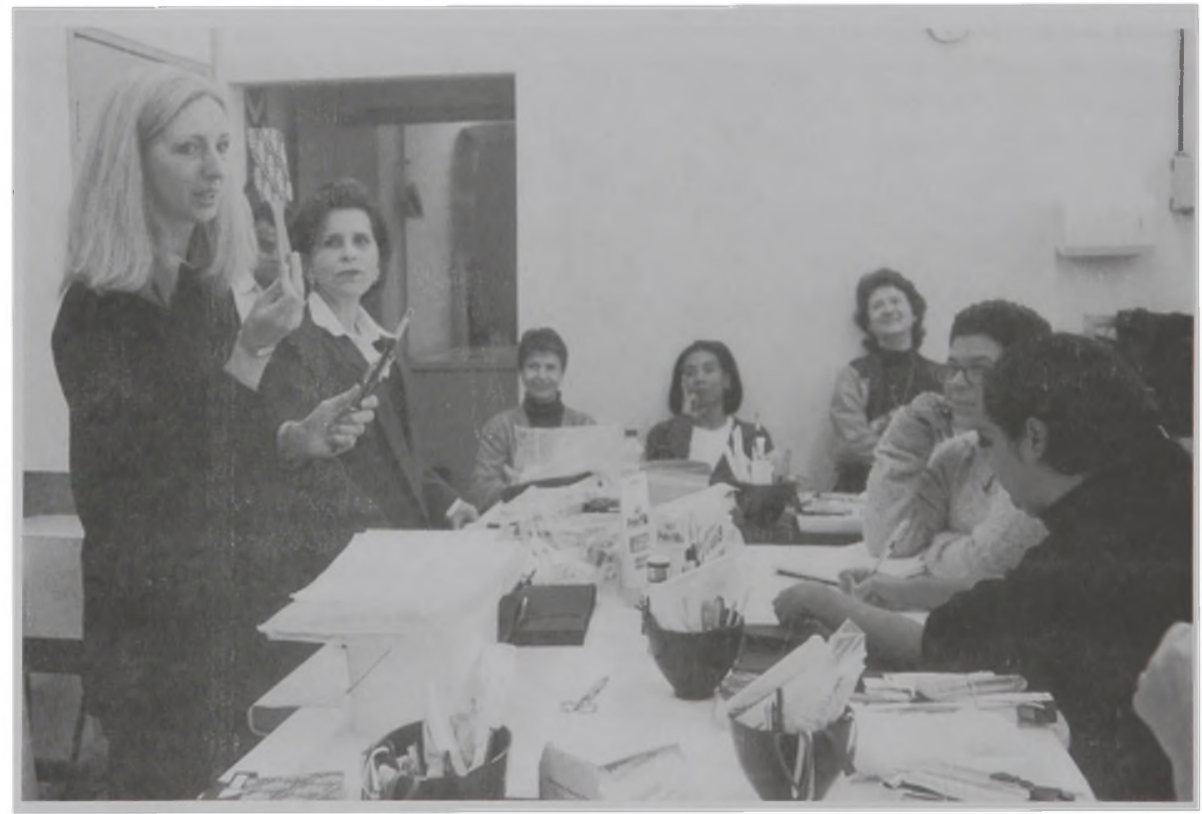

Apresentação dos materiais aos participantes.

instituições (em pontos distintos do país) o seu vaso com seus fragmentos reconstituídos com vários tipos de adesivos e a observarem o comportamento das uniões efetuadas em seus ambientes (diversos tipos de temperatura e umidade relativa no país).

Um dia especial foi reservado para a visita aos Módulos de Arqueologia e Artes Indíge- 
nas da Mostra do Redescobrimento, no Pavilhão Lucas Nogueira Garcez (Oca), no Parque do Ibirapuera. Nesta oportunidade, todos os participantes do workshop se encontraram com todos os curadores da exposição Unknown Amazon para uma discussão quanto ao estado de conservação das peças expostas, principalmente aquelas que poderiam ser selecionadas para a exposição no British Museum. Os curadores falaram da expectativa quanto aos resultados de possíveis tratamentos. Os instrutores analisaram as peças expostas com diferentes graus de intervenções: se estas eram adequadas ou inadequadas, excessivas ou não, opcionais ou obrigatórias (para garantir a estabilidade do objeto). Foram discutidos aspectos como a fragilidade de certas peças, se elas poderiam viajar, como deveriam ser manuseadas e expostas, se poderiam ser limpas ou terem certas intervenções removidas, preenchimentos de lacunas, refazer ou não as partes faltantes. Nestas discussões ficavam claros alguns aspectos subjetivos ou éticos da restauração: principalmente aqueles que se referiam à apresentação estética dos objetos (formas diferentes de reintegração cromática), preenchimento ou recomposição de perdas. As características mais relacionadas com a segurança e conservação das peças através da mínima intervenção também foram lembradas.

As discussões foram ricas e acaloradas diante de tantas peças com restaurações antigas, realizadas quando ainda não estavam em prática os princípios básicos da conservação científica (ou porque ainda não haviam sido postulados ou porque eram desconhecidos pelos antigos restauradores).

Recebido para publicação em 15 de agosto de 2000.

\section{Conclusão}

Durante o workshop, ao longo da jornada teórica e prática, os vários especialistas puderam trocar informações relevantes quanto à forma de atuação na conservação de materiais cerâmicos arqueológicos, confrontando suas respectivas metodologias com os procedimentos habitualmente aplicados no British Museum. $O$ intercâmbio foi extremamente enriquecedor, levando-se em consideração as grandes diferenças regionais no nosso país e na Inglaterra. Os objetivos iniciais de se criar a oportunidade para a discussão de uma linguagem uniforme e coerente com a proposta de critérios de conservação direcionados à exposição "Unknown Amazon" puderam ser alcançados, sendo a possibilidade de aplicação destas experiências adequadas às diferentes realidades regionais e formações profissionais dos participantes do curso.

Nesta oportunidade se estabeleceu, também, um diálogo entre as áreas científicas do British Museum e o MAE/USP.

\section{Agradecimentos}

Aos curadores Cristiana Barreto, Eduardo Góes Neves e Colin McEwan. Fleming

À Profa. Dra. Maria Isabel D’Agostino

Ângela de Menezes Freitas

À Associação Brasil +500 Anos

Ao MAE/USP e ao Bristish Museum

Gedley Belchior Braga* Moema Nascimento Queiroz**

(*) Laboratório de Conservação e Restauro do Serviço de Curadoria do Museu de Arqueologia e Etnologia - Universidade de São Paulo.

(**) CECOR, Centro de Conservação e Restauração da Escola de Belas Artes da Universidade Federal de Minas Gerais. 